\title{
Metastatic polyp of the gallbladder from renal cell carcinoma
}

\author{
Bor-Uei Shyr ${ }^{1}$, Shih-Chin Chen ${ }^{1}$, Yi-Ming Shyr ${ }^{1}$, Rheun-Chuan Lee ${ }^{2}$ and Shin-E Wang ${ }^{1 *}$
}

\begin{abstract}
Background: Gallbladder metastasis from renal cell carcinoma (RCC) is extremely rare. The purpose of this study is to clarify the characteristics of metastatic RCC to gallbladder.

Methods: The pooled data for analysis were collected from the case of metastatic RCC to gallbladder encountered by our institution along with sporadic cases reported in literature from 1991 to 2015.

Results: A total of 50 cases of metastatic RCC to gallbladder were recruited for study. Fifty-seven percentage of the primary RCC was from the right kidney and $43 \%$ from the left. The median interval between diagnoses of primary and metastatic RCC to gallbladder was 36 months, with the longest duration up to 324 months. Most (70\%) were asymptomatic. The size of metastatic RCC to gallbladder ranged from $0.8 \mathrm{~cm}$ to $9 \mathrm{~cm}$, with median of $2.6 \mathrm{~cm}$. Majority (91\%) of the metastatic RCCs presented as a polypoid mass with narrow stalk, and $82 \%$ were hypervascular lesion. The overall 1 year, 3 year and 5 year survival rate was 91.5\%, 76.2\% and 59.3\% respectively, with a median of 26.5 months. Number of the metastatic site, timing of gallbladder metastasis, symptom, tumor size and operation type of cholecystectomy seemed to have no impact on survival.

Conclusions: Metastatic RCC to the gallbladder should be taken into account for a gallbladder polypoid mass with narrow hypervascular stalk during the diagnosis and/or follow-up of primary RCC. Gallbladder metastasis from RCC is not necessarily to be an advanced stage with poor outcome, and cholecystectomy is recommended whenever possible.
\end{abstract}

Keywords: Gallbladder, Metastasis, Renal cell carcinoma

\section{Background}

Metastasis to the gallbladder has been considered rare, and reported from a variety of primary sites, it usually manifests at a late and advanced stage of malignancy [1-3]. It is estimated that $30 \%-40 \%$ of patients with RCC have already had synchronous metastasis at time of presentation and another $20 \%-50 \%$ will develop metachronous metastasis after nephrectomy for the primary RCC $[2,4-6]$. The common sites of RCC metastasis are lung, bone, liver, brain, adrenal and contralateral kidney. Gallbladder metastasis from RCC has been reported sporadic, and considered extremely rare [7-10]. it is usually detected only at autopsy with a rate of less than $0.6 \%$ [10]. Clinical diagnosis of

\footnotetext{
* Correspondence: sewang0408@gmail.com

${ }^{1}$ Division of General Surgery, Department of Surgery, Taipei Veterans General Hospital and National Yang Ming University, 10 F 201 Section 2 Shipai Road, Taipei 112, Taiwan

Full list of author information is available at the end of the article
}

gallbladder metastasis is even rarer $[3,11,12,5,7,8]$. Patients with distant metastasis from RCC usually present a poor prognosis, with a 5-year survival rate of $<10 \%$. Nevertheless, it is well-known that complete resection of metastasis could have long-term survival in selected patients with pancreas metastasis of RCC [13]. This favorable prognosis might also be the case for those with gallbladder metastasis [11].

The purposes of this article are to present our clinical experience with metastatic polyp of the gallbladder from RCC and to analyze an expanded sample size by adding cases reported in the literature to our pool of the study cases. Thus, a statistic attempt is made to clarify the demographics, clinical presentations, managements and survival outcomes of this rare tumor. 


\section{Methods}

Brief description was made for the case of metastatic polyp of the gallbladder from RCC encountered at our institution. The study has been approved by the Institutional Review Board of Taipei Veterans General Hospital (IRB-TPEVGH No.: 2017-03-006BAC). Appropriate written informed consent to participate was obtained from the patients. Data and materials described in the manuscript, including all relevant raw data, will be freely available to any scientist wishing to use them for non-commercial purposes, without breaching participant confidentiality. To clarify the characteristics of metastatic RCC to gallbladder, individualized data of these cases described in the English literature were extracted and added to our database to expand the study sample size for a more complete analysis. Two methods were utilized to search for relevant cases in the literature. First, to identify the relevant articles dealing with metastatic RCC to gallbladder in the English literature, a computerized search was performed on the PubMed electronic database, covering data from 1991 to 2015. The following keywords were used for the PubMed search: metastatic renal cell carcinoma and gallbladder, gallbladder metastasis and renal cell carcinoma, renal cell carcinoma metastasis and gallbladder. Second, the reference lists of PubMed-selected metastatic RCC to gallbladder articles were screened systematically for additional studies of interest. A total of 35 related articles were selected for study [1-5, 7-9, 11, 12, 14-38].

Cases without individualized data and duplicate cases reported in literature were excluded from the analysis. The data pool from the related literature cases and our patient were analyzed to determine the characteristics of metastatic RCC to gallbladder including demographics, primary renal cell carcinoma, clinical presentations of RCC metastasis to gallbladder, timing of metastasis, concomitant metastasis to other site, and survival outcomes whenever possible.

Statistical analyses were performed using Statistical Product and Service Solutions (SPSS) version 21.0 software (SPSS Inc., IBM, Armonk, NY, USA). All continuous data were presented as median (range) and mean \pm standard deviation (SD), and case number (\%) were presented when appropriate to the type of data. Actuarial survival was estimated via the Kaplan-Meier method, and a log rank test was used to determine differences in the subgroups. For all analyses, a $P$ value less than 0.050 was considered statistically significant.

\section{Results}

A total of 50 cases of metastatic RCC to the gallbladder were collected for study, including 49 cases from the literature and 1 from our institution. Our case, an 80-yearold man, was diagnosed with a gallbladder tumor during a postoperative surveillance follow-up by sonography which showed a big hypoechoic $3.6 \times 3.7 \mathrm{~cm}$ mass (Fig. 1a) with a hypervascular stalk (Fig. 1b) to gallbladder fundus in November 2011. The patient had a history of radical nephrectomy for right RCC with stage of pT1aN0M0 in November 1997. Magnetic resonance imaging (MRI) revealed a $4.2 \times 3.4 \mathrm{~cm}$ pedunculated polypoid lesion arising from gallbladder fundus. The polypoid gallbladder tumor demonstrated intermediate signal intensity on T1-weighted

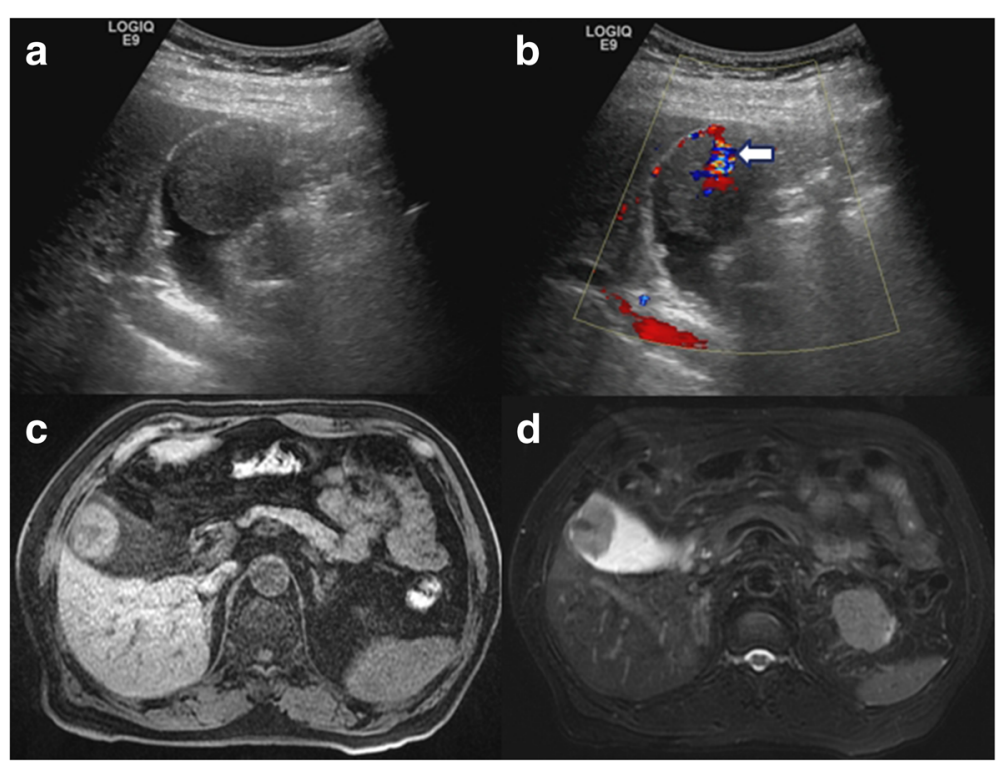

Fig. 1 The gray-scale (a) and color Doppler sonography (b) show arterial flow (white arrow) within the polypoid mass from the cystic artery. On the T1-weighted fat-saturated spoiled gradient recalled echo (c) and fat-saturated T2 fast spin-echo MRI images (d), the polypoid gallbladder tumor demonstrates intermediate signal intensity on T1-weighted image and slightly high on T2-weighted image to that of liver parenchyma 
image (Fig. 1c), slightly high on T2-weighted image (Fig. 1d), and high intensity on diffusion-weighted image. Serum tumor markers including alpha-fetoprotein (AFP), carbohydrate antigen 19-9 (CA 19-9) and carcinoembryonic antigen (CEA) were all within normal limit. The patient underwent an open cholecystectomy under the impression of gallbladder polyp with malignant change in March 2012. The resected specimen showed a big wellcircumscribed polypoid mass with a narrow stalk (Fig. 2) attached to the gallbladder fundus, and the turned out to be a metastatic RCC by pathologic examination. The patient recovered uneventfully and remained disease-free without further adjuvant therapy for 3.5 years.

Analysis of the pooled data (Table 1) indicated that $63 \%$ patients were male and $37 \%$ were female. The metastatic RCC to the gallbladder occurred at a median age of 62 years, ranging from 39 to 80 years. Fifty-seven percentage of the primary RCC was from the right kidney and $43 \%$ from the left. Size of primary RCC ranged from $0.4 \mathrm{~cm}$ to $12.2 \mathrm{~cm}$ with a median of $7.8 \mathrm{~cm}$. Majority (75\%) of RCC metastasis to the gallbladder were metachronous. The median interval between diagnoses of primary and metastatic RCC to gallbladder for the metachronous metastasis was 60 months, with the longest duration up to 324 months. Most (70\%) were asymptomatic, while epigastric pain was the most common presentation $23 \%$ in symptomatic patients. The polypoid mass in gallbladder was found by sonography in $93 \%$, by computed tomography (CT) in $80 \%$, and by magnetic resonance imaging (MRI) in $21 \%$.

Table 2 described the diagnosis and characteristics of gallbladder metastasis from RCC. Preoperative diagnosis suspected metastatic RCC to gallbladder in $44 \%$, gallbladder polyp in $27 \%$ and gallbladder cancer in $17 \%$. The size of metastatic RCC to gallbladder ranged from $0.8 \mathrm{~cm}$ to $9 \mathrm{~cm}$, with median of $2.6 \mathrm{~cm}$. Majority (91\%) of the metastatic RCCs presented as a polypoid mass with narrow stalk, and

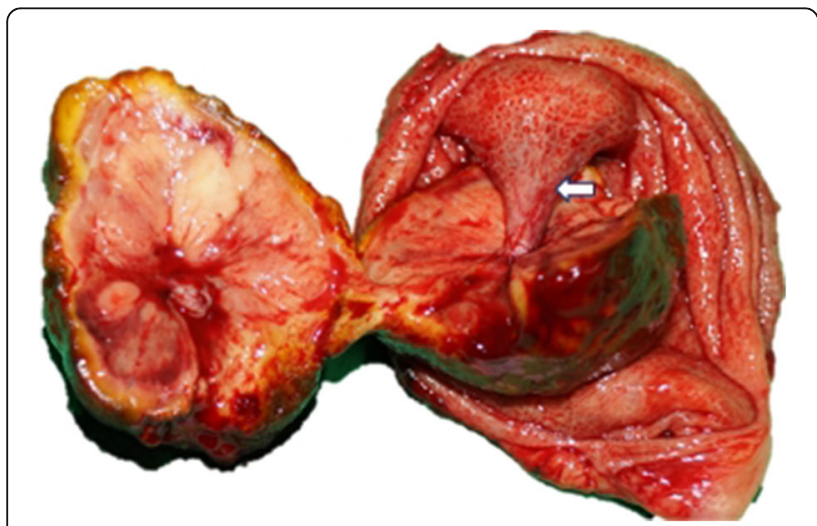

Fig. 2 The metastatic renal cell carcinoma presents a wellcircumscribed polypoid mass with a narrow stalk (white arrow) to the fundus of gallbladder
Table 1 Demographics and clinical presentations of gallbladder metastasis from RCC

\begin{tabular}{|c|c|}
\hline \multicolumn{2}{|l|}{ Sex, $n=40$} \\
\hline Male & $25(63 \%)$ \\
\hline Female & 15 (37\%) \\
\hline \multicolumn{2}{|l|}{ Age, $y / o, n=39$} \\
\hline Median (range) & $62(39-80)$ \\
\hline Mean's & $61 \pm 12$ \\
\hline \multicolumn{2}{|c|}{ Laterality of primary RCC, $n=42$} \\
\hline Right & $24(57 \%)$ \\
\hline Left & $18(43 \%)$ \\
\hline \multicolumn{2}{|c|}{ Size of primary $\mathrm{RCC}, \mathrm{cm}, n=20$} \\
\hline Median (range) & $7.8(0.4-12.2)$ \\
\hline Mean \pm SD & $7.2 \pm 3.3$ \\
\hline \multicolumn{2}{|c|}{ Timing of gallbladder metastasis, $n=48$} \\
\hline Synchromous & $12(25 \%)$ \\
\hline Metachronous & $36(75 \%)$ \\
\hline \multicolumn{2}{|c|}{ Interval of metachronous metastasis, month, $n=33$} \\
\hline Median (range) & $60(1-324)$ \\
\hline Mean \pm SD & $79.4 \pm 58.2$ \\
\hline \multicolumn{2}{|l|}{ Symptoms, $n=43$} \\
\hline No & $30(70 \%)$ \\
\hline Epigastric pain & $10(23 \%)$ \\
\hline Nausea or vomiting & $4(9 \%)$ \\
\hline Epigastric fullness & $3(7 \%)$ \\
\hline Body weight loss & $2(5 \%)$ \\
\hline Jaundice & $1(2 \%)$ \\
\hline \multicolumn{2}{|c|}{ Duration of symptom, month, $n=37$} \\
\hline Median (range) & $0(0-6)$ \\
\hline Mean \pm SD & $0.3 \pm 1.0$ \\
\hline \multicolumn{2}{|l|}{ Diagnosis method } \\
\hline Sonography, $n=42$ & $39(92.9 \%)$ \\
\hline CT scan, $n=44$ & $35(79.5 \%)$ \\
\hline $\mathrm{MRI}, n=39$ & $8(20.5 \%)$ \\
\hline
\end{tabular}

$R C C$ renal cell carcinoma, $S D$ standard deviation, $M R I$ magnetic resonance imaging, $C T$ computed tomography

$82 \%$ were hypervascular lesion by image studies. The metastatic RCC was located on gallbladder fundus in $48 \%$, body in $41 \%$ and neck in $12 \%$. Most (72\%) of the metastatic RCCs to the gallbladder were not associated with gallstone. Multiple metastasis occurred in $28 \%$ at the diagnosis of metastatic RCC to gallbladder, and the most common concomitant additional site of RCC metastasis was contralateral kidney and lung (12.8\%), followed by bone (6.4\%).

Eighty-seven percentage of patients were treated with cholecystectomy by open laparotomy, $13 \%$ by laparoscopic approach, and 25\% received additional adjuvant therapy. Two-thirds of patients had no recurrence. The 
Table 2 Diagnosis and characteristics of gallbladder metastasis from RCC

\begin{tabular}{|c|c|}
\hline \multicolumn{2}{|l|}{ Preoperative diagnosis, $n=41$} \\
\hline Gallbladder metastasis from RCC & $18(44 \%)$ \\
\hline Gallbladder polyp & $11(27 \%)$ \\
\hline Gallbladder cancer & $7(17 \%)$ \\
\hline Acute cholecystitis & $3(7 \%)$ \\
\hline Gallstone & $2(5 \%)$ \\
\hline \multicolumn{2}{|l|}{ Size of metastatic RCC to gallbladder, $\mathrm{cm}, n=40$} \\
\hline Median (range) & $2.6(0.8-9)$ \\
\hline Mean \pm SD & $2.9 \pm 1.8$ \\
\hline \multicolumn{2}{|l|}{ Vascularity of metastatic RCC to gallbladder, $n=27$} \\
\hline Hypervascular & $22(82 \%)$ \\
\hline Heterogenous & $5(18 \%)$ \\
\hline \multicolumn{2}{|l|}{ Location of metastatic RCC in gallbladder, $n=42$} \\
\hline Fundus & $20(48 \%)$ \\
\hline Body & $17(40 \%)$ \\
\hline Neck & $5(12 \%)$ \\
\hline \multicolumn{2}{|l|}{ Appearance of metastatic RCC in gallbladder, $n=42$} \\
\hline Polypoid mass with narrow stalk to gallbladder & $38(91 \%)$ \\
\hline Polypoid mass with wide base to gallbladder & $4(9 \%)$ \\
\hline \multicolumn{2}{|l|}{ Presence of gallbladder stone, $n=39$} \\
\hline No & $28(72 \%)$ \\
\hline Yes & $11(28 \%)$ \\
\hline Concomitant multiple metastasis, $n=47$ & $13(28 \%)$ \\
\hline Contralateral kidney & $6(13 \%)$ \\
\hline Lung & $6(13 \%)$ \\
\hline Bone & $3(6 \%)$ \\
\hline Adrenal & $2(4 \%)$ \\
\hline Pancreas & $1(2 \%)$ \\
\hline
\end{tabular}

$R C C$ renal cell carcinoma, $S D$ standard deviation

overall 1 year, 3 year and 5 year survival was 91.5\%, $76.2 \%$ and $59.3 \%$ respectively, with a median of 26.5 months (1-132 months) (Table 3$)$. Number of the metastatic site, timing of metastasis gallstone, symptom, tumor size and operation type of cholecystectomy seemed to have no survival impact.

\section{Discussion}

Metastatic gallbladder tumors are not common, about $4.8 \%$ of all gallbladder malignancies [39]. melanoma, stomach cancer, RCCs, hepatocellular carcinoma, colorectal cancer, breast cancer, and lung cancers have been reported to be the common cancers that could metastasize to the gallbladder [3, 4, 39]. RCC, accounting for $3 \%$ of all malignancies in adults and $85 \%$ of primary renal tumors, has a great propensity to develop synchronous or metachronous metastasis to various anatomic sites $[1,40]$. Moreover, late and solitary metastasis have been a unique clinical presentation for RCC after nephrectromy [13].

This study found gallbladder metastasis from RCC occurred with male predominance $(63 \%)$, and at a median age of 62 years. Although the gallbladder is in right abdomen, primary RCC could be from either the right (57\%) or left kidney (43\%). Most (75\%) of gallbladder metastases from RCC were metachronous. The median time to gallbladder metastasis following nephrectomy in metachronous cohort was 5 years, with longest one up to 27 years. Majority (72\%) were solitary gallbladder metastasis without other site metastasis at the time of diagnosis. The unique clinical entity of solitary and late metachronous metastasis seems to be observed not only in other organs such as pancreas [13] but also in gallbladder. Although the median tumor size was $2.6 \mathrm{~cm}$, most $(70 \%)$ of the patients remained asymptomatic at the time of diagnosis and/or follow-up of primary RCC. The low association (28\%) of gallstone might explain the silent clinical presentation.

Although gallbladder polyp (27\%), gallbladder cancer (17\%) and acute cholecystitis (7\%) were considered in some patients preoperatively, metastatic RCC to the gallbladder was nevertheless on the priority diagnosis in $44 \%$ cases with the history of primary RCC. In this study, we found most (91\%) of the metastatic RCCs presented as a polypoid mass with narrow stalk, and $82 \%$ were hypervascular lesion by image studies. It has been observed that metastatic adenocarcinoma of the GB manifested as infiltrative and persistently enhancing wall thickenings, while the metastatic non-adenocarcinoma such as RCC usually manifested as a polypoid lesion in the gallbladder by computed tomography (CT) imaging study $[3,4,14]$. Some imaging studies with ultrasound, CT scan or MRI also showed a hypervascular polypoid mass like that of our case $[4,14]$. The metastatic polypoid mass showed high intensity on diffusion-weighted images, and the apparent diffusion coefficient was relatively low on MRI. These imaging findings are considered characteristic and may be helpful for preoperative diagnosis $[4,14]$. Therefore, metastatic RCC should be taken into account for a gallbladder polyp with narrow hypervascular stalk, especially for those with the history of RCC.

Gallbladder metastasis from RCC is not necessarily to be an advanced stage with poor outcome, especially for those with late and solitary metastasis $[4,7,12,13]$. Based on the experience in the more typical metastatic sites such as pancreas, lung bone, resectability, long time to recurrence, good performance status and oligometastatic disease have better benefit of metastasectomy [10, 13, 41]. Cholecystectomy should be considered because only such management could provide an opportunity for longer survival $[16,25-27,34]$. This study revealed the median 
Table 3 Survival outcomes of gallbladder metastasis from RCC

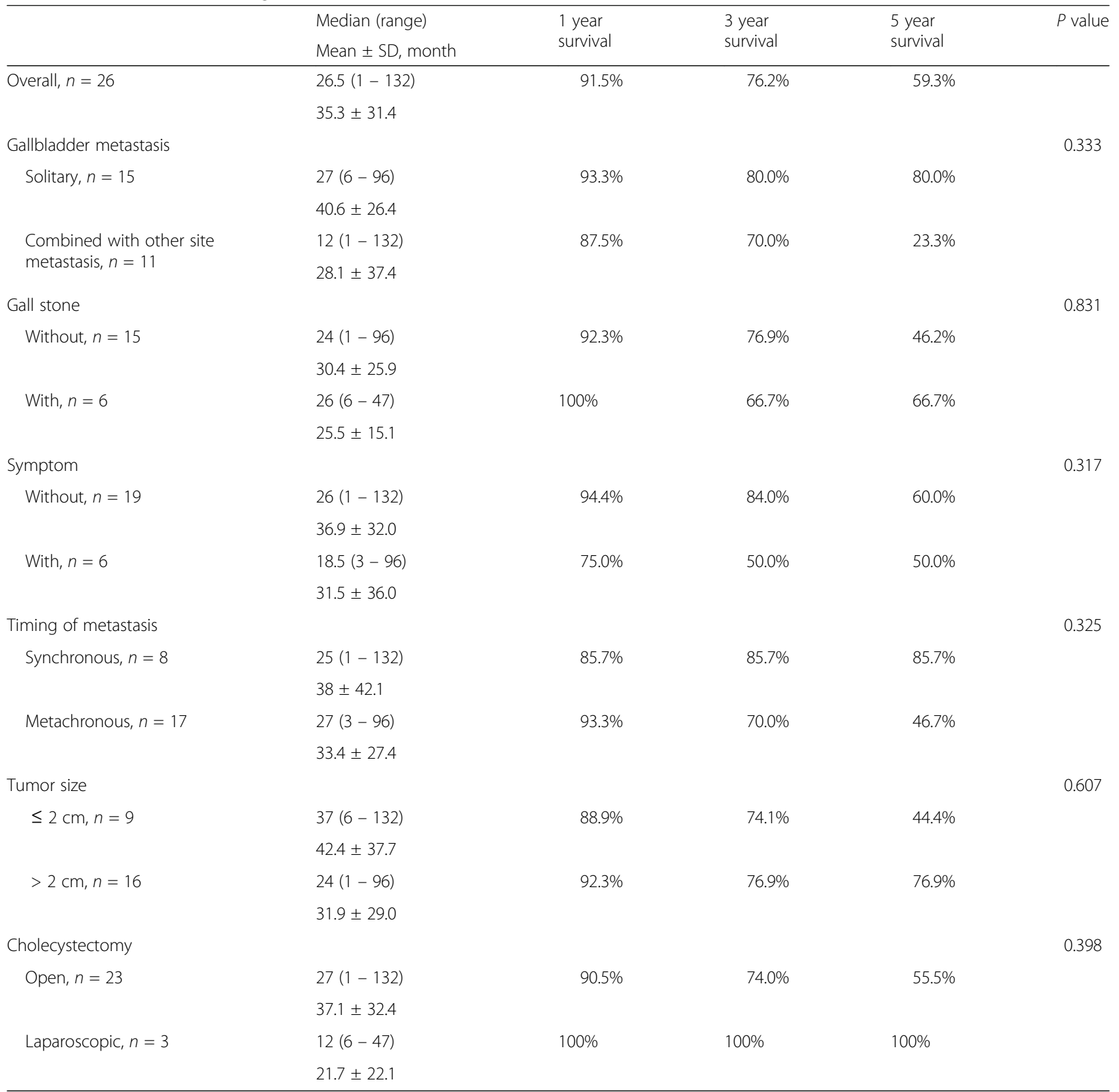

survival time was 26.5 months, with 91.5\% 1-year and $59.3 \%$ 5-year survival. A multivariate analysis showed that favorable predictors of survival for metastatic RCC included single site of first recurrence, curative resection of first metastasis, long disease-free interval, solitary site of first metastasis, and metachronous metastasis [42]. It is also shown that the longer interval between diagnosis of RCC and gallbladder metastasis the better the survival [15]. In this study, number of the metastatic site, timing of metastasis gallstone, symptom, tumor size and operation type of cholecystectomy seemed to have no survival impact. However, it is hard to draw a solid conclusion from this retrospective study with a small sample size.

\section{Conclusions}

Gallbladder metastasis from RCC is a rare but unique clinical entity. Metastatic RCC should be taken into account for a gallbladder polypoid mass with narrow hypervascular stalk at the diagnosis and/or follow-up of primary RCC. Gallbladder metastasis from RCC is not necessarily to be an advanced stage with poor outcome, especially for those with late and solitary metastasis. 
Cholecystectomy should be considered to determine the definitive diagnosis and provide better survival outcome whenever possible.

\section{Abbreviations}

AFP: Alpha-fetoprotein; CA 19-9: Carbohydrate antigen 19-9;

CEA: Carcinoembryonic antigen; CT: Computed tomography; MRI: Magnetic resonance imaging; RCC: Renal cell carcinoma

\section{Acknowledgements}

Not applicable.

\section{Funding}

Not applicable.

\section{Availability of data and materials}

Data and materials described in the manuscript, including all relevant raw data, will be freely available to any scientist wishing to use them for noncommercial purposes, without breaching participant confidentiality.

\section{Authors' contributions}

SBU and SYM equally contributed to this paper. SBU and SYM made substantial contributions to conception and design, acquisition of data, and analysis and interpretation of data. CSC was involved in drafting the manuscript or revising it critically for important intellectual content. LRC was involved in drafting the manuscript or revising it critically for important intellectual content and agreed to be accountable for all aspects of the imaging studies in ensuring that questions related to the accuracy. WSE made substantial contributions to conception and design, acquisition of data, and analysis and interpretation of data and gave final approval of the version to be published. All authors read and approved the final manuscript.

\section{Competing interests}

The authors declare that they have no competing interests.

\section{Consent for publication}

Not applicable.

\section{Ethics approval and consent to participate}

The study has been approved by the Institutional Review Board of Taipei Veterans General Hospital (IRB-TPEVGH No.: IRB-TPEVGH No:: 2017-03-006BAC). Appropriate written informed consent to participate was obtained from the patients.

\section{Publisher's Note}

Springer Nature remains neutral with regard to jurisdictional claims in published maps and institutional affiliations.

\section{Author details}

'Division of General Surgery, Department of Surgery, Taipei Veterans General Hospital and National Yang Ming University, 10 F 201 Section 2 Shipai Road, Taipei 112, Taiwan. ${ }^{2}$ Departments of Radiology, Taipei Veterans General Hospital, National Yang Ming University, Taipei, Taiwan.

Received: 31 October 2016 Accepted: 29 March 2017 Published online: 04 April 2017

\section{References}

1. Ghaouti M, Znati K, Jahid A, Zouaidia F, Bernoussi Z, El Fakir Y, Mahassini N. A gallbladder tumor revealing metastatic clear cell renal carcinoma: report of case and review of literature. Diagn Pathol. 2013:8:4

2. Turner $G$, Flint R. Metastatic renal cell carcinoma-an unexpected finding after laparoscopic cholecystectomy. N Z Med J. 2014;127(1402):110-2.

3. Choi WS, Kim SH, Lee ES, Lee KB, Yoon WJ, Shin Cl, Han JK. CT findings of gallbladder metastases: emphasis on differences according to primary tumors. Korean J Radiol. 2014:15(3):334-45.

4. Chung PH, Srinivasan R, Linehan WM, Pinto PA, Bratslavsky G. Renal cell carcinoma with metastases to the gallbladder: four cases from the National Cancer Institute (NCl) and review of the literature. Urol Oncol. 2012;30(4):476-81.

5. Win AZ. Renal cell carcinoma metastasis to the gallbladder detected by FDG-PET/CT. J Clin Med Res. 2014;6(6):482-6.
6. Press GA, McClennan BL, Melson GL, Weyman PJ, Mauro MA, Lee JK. Papillary renal cell carcinoma: CT and sonographic evaluation. AJR Am J Roentgenol. 1984;143(5):1005-9.

7. Fang X, Gupta N, Shen SS, Tamboli P, Charnsangavej C, Rashid A, Wang H. Intraluminal polypoid metastasis of renal cell carcinoma in gallbladder mimicking gallbladder polyp. Arch Pathol Lab Med. 2010;134(7):1003-9.

8. Patel S, Zebian B, Gurjar S, Pavithran N, Singh K, Liston T, Grant J. An unusual gall-bladder polyp-site of metastatic renal cell carcinoma: a case report. Cases J. 2009:2:172.

9. Kawahara T, Ohshiro H, Sekiguchi Z, Furuya M, Namura K, Itoh H, Sano F Kawaji K, Hayashi N, Makiyama K, et al. Gallbladder metastasis from renal cell carcinoma. Case Rep Oncol. 2010;3(1):30-4.

10. Weiss L, Harlos JP, Torhorst J, Gunthard B, Hartveit F, Svendsen E, Huang WL, Grundmann E, Eder M, Zwicknagl M, et al. Metastatic patterns of renal carcinoma: an analysis of 687 necropsies. J Cancer Res Clin Oncol. 1988; 114(6):605-12

11. Shoji S, Mukai M, Yazawa N, Sekido Y, Nagata Y, Uchida T, Terachi T. Metastasis to gallbladder and adrenal gland of renal cell carcinoma. Onco Lett. 2010;1(3):507-9.

12. Zevallos Quiroz JC, Lizarazu Perez A, Guisasola Gorrochategui E, Medrano Gomez MA, Jimenez Aguero R. Gallbladder metastasis from renal cell carcinoma, an extremely rare neoplastic dissemination location. Cirugia Espanola. 2014;92(4):295-6.

13. Hung JH, Wang SE, Shyr YM, Su CH, Chen TH, Wu CW. Resection for secondary malignancy of the pancreas. Pancreas. 2012;41(1):121-9.

14. Ueda I, Aoki T, Oki H, Takahashi H, Hayashida Y, Minagawa N, Yamaguchi K, Fujimoto N, Matsumoto T, Yamada S, et al. Gallbladder metastasis from renal cell carcinoma: a case report with review of the literature. Magn Reson Med Sci. 2015;14(2):133-8.

15. Jain D, Chopra P. Metastatic renal cell carcinoma of gall bladder. Saudi J Kidney Dis Transpl. 2013;24(1):100-4.

16. Zygulska AL, Wojcik A, Richter P, Krzesiwo K. Renal carcinoma metachronous metastases to the gall-bladder and pancreas-case report. Pol Przegl Chir. 2012;84(6):313-6.

17. Robledo AB, Millet SB, Orbis Castellanos JF, Montalva Oron EM, Salom Fuste JV, DE Juan Burgueño M. Metastasis of the gallbladder in clear cell renal carcinoma. Oncol Lett. 2012;3(5):1136-8.

18. Collin Y, Sabbagh R. An unusual case of pancreatitis revealing a metachronous renal cell carcinoma metastasis to the gallbladder. Can J Urol. 2012;19(4):6392-4.

19. Decoene J, Ameye F, Lerut E, Oyen R, Van Poppel H, Joniau S. Renal cell carcinoma with synchronous metastasis to the calcaneus and metachronous metastases to the ovary and gallbladder. Case Rep Med. 2011;2011:671645

20. Sand M, Bechara FG, Kopp J, Krins N, Behringer D, Mann B. Gallbladder metastasis from renal cell carcinoma mimicking acute cholecystitis. Eur J Med Res. 2009:14:90-2.

21. Kucukakin B, Olsen CH, Gogenur I. Renal cell carcinoma with metachronous metastases to the gallbladder after two years. Ugeskr Laeger. 2009:171(35):2486-7.

22. Nojima H, Cho A, Yamamoto H, Nagata M, Takiguchi N, Kainuma O, Souda H, Gunji H, Miyazaki A, Ikeda A, et al. Renal cell carcinoma with unusual metastasis to the gallbladder. J Hepato-Biliary-Pancreat Surg. 2008;15(2):209-12.

23. Hellenthal NJ, Stewart GS, Cambio AJ, Delair SM. Renal cell carcinoma metastatic to gallbladder: a survival advantage to simultaneous nephrectomy and cholecystectomy. Int Urol Nephrol. 2007:39(2):377-9.

24. Pandey D, Kane SV, Shukla PJ, Shrikhande SV, Tongaonkar HB. Isolated gall bladder metastasis from renal cell carcinoma. Indian J Gastroenterol. 2006; 25(3):161-2.

25. Ishizawa T, Okuda J, Kawanishi T, Kitagawa T, Yakumaru K, Sekikawa T. Metastatic renal cell carcinoma of the gallbladder. Asian J Surg. 2006;29(3):145-8.

26. Park JS, Chae YS, Hong SJ, Shin DH, Choi JS, Kim BR. Metastatic renal cell carcinoma of the gallbladder. Yonsei Med J. 2003:44(2):355-8.

27. Limani K, Matos C, Hut F, Gelin M, Closset J. Metastatic carcinoma of the gallbladder after a renal cell carcinoma. Acta Chir Belg. 2003:103(2):233-4.

28. Aoki T, Inoue K, Tsuchida A, Aoki T, Kasuya K, Kitamura K, Koyanagi Y, Shimizu T. Gallbladder metastasis of renal cell carcinoma: report of two cases. Surg Today. 2002;32(1):89-92

29. Kechrid M, Malik GH, Al-Mohaya S, Shaikh JF, Al-Wakeel JS, El Gamal H, Farouk H, Jasser A, Shetia MS. Renal cell carcinoma of contralateral kidney with secondaries in gallbladder eight years after nephrectomy. Saudi J Kidney Dis Transpl. 2000;11(4):587-92. 
30. Celebi I, Guzelsoy M, Yorukoglu K, Kirkali Z. Renal cell carcinoma with gallbladder metastasis. Int J Urol. 1998;5(3):288-90.

31. Sparwasser C, Krupienski M, Radomsky J, Pust RA. Gallbladder metastasis of renal cell carcinoma. A case report and review of the literature. Urol Int. 1997;58(4):257-8.

32. Lombardo FP, Hertford DE, Shanahan EM, Kazam E. Color Doppler ultrasonographic evaluation of renal cell carcinoma metastasis to the gallbladder. J Ultrasound Med. 1996;15(10):725-8.

33. Pagano S, Ruggeri P, Franzoso F, Brusamolino R. Unusual renal cell carcinoma metastasis to the gallbladder. Urology. 1995;45(5):867-9.

34. King DH, Centeno AS, Saldivar VA, Sarosdy MF. Renal cell carcinoma metastatic to the gallbladder or prostate: two case reports. Urology. 1995:46(5):722-5.

35. Coskun F, Cetinkaya M, Cengiz O, Adsan O, Kulacoglu S, Eroglu A. Metastatic carcinoma of the gallbladder due to renal cell carcinoma in the ectopic kidney. Acta Chir Belg. 1995;95(1):56-8.

36. Bittinger A, Altekrüger I, Barth P. Clear cell carcinoma of the gallbladder. Pathol Res Pract. 1995;191(12):1259-65.

37. Nagler J, McSherry CK, Miskovitz P. Asymptomatic metachronous metastatic renal cell adenocarcinoma to the gallbladder. Report of a case and guidelines for evaluation of intraluminal polypoid gallbladder masses. Dig Dis Sci. 1994:39(11):2476-9.

38. Satoh H, lyama A, Hidaka K, Nakashiro H, Harada S, Hisatsugu T. Metastatic carcinoma of the gallbladder from renal cancer presenting as intraluminal polypoid mass. Dig Dis Sci. 1991;36(4):520-3.

39. Yoon WJ, Yoon YB, Kim YJ, Ryu JK, Kim YT. Metastasis to the gallbladder: a single-center experience of 20 cases in South Korea. World J Gastroenterol. 2009;15(38):4806-9.

40. Choi JB, Yoon BI, Kim SJ, Cho HJ, Hong SH, Choi YJ, Kim SW, Hwang TK, Lee JY. Changes in clinicopathological characteristics of renal cell carcinoma in the past 25 years: a single-center experience. Korean J Urol. 2011;52(2):110-4.

41. Dabestani S, Marconi L, Bex A. Metastasis therapies for renal cancer. Curr Opin Urol. 2016;26(6):566-72.

42. Kavolius JP, Mastorakos DP, Pavlovich C, Russo P, Burt ME, Brady MS. Resection of metastatic renal cell carcinoma. J Clin Oncol. 1998;16(6):2261-6.

\section{Submit your next manuscript to BioMed Central and we will help you at every step:}

- We accept pre-submission inquiries

- Our selector tool helps you to find the most relevant journal

- We provide round the clock customer support

- Convenient online submission

- Thorough peer review

- Inclusion in PubMed and all major indexing services

- Maximum visibility for your research

Submit your manuscript at www.biomedcentral.com/submit

) Biomed Central 